\title{
Blue Water, Green Tea: Socio-innovation, Taiwan
}

\author{
Shenglin Elijah Chang \\ Graduate Institute of Building and Planning, \\ National Taiwan University, Taiwan \\ shenglin@ntu.edu.tw
}

\begin{abstract}
The research experiments how to revitalize a very depressed Pinglin within the eco-protected Taipei Water Special Area in the peri-urban Taiwan. Based on action research rooted in social innovation, the team develops ecological-oriented strategies to revitalize Pinglin area. Three socio-ecological innovative strategies include (1) product: eco-friendly fair-trade Blue Magpie Tea, (2) process: eco-tea tourism, (3) promise: eco-tea farmers' children tutoring. Branding the eco-friendly "Blue Magpie Tea" has inspired the young coffee drinkers to taste tea. All actions help rebuild Pinglin's identity as an ecotea country.
\end{abstract}

Keywords: Social innovation; tea landscape; peri-urban; Taiwan

eISSN: 2398-4279 @ 2016. The Authors. Published for AMER ABRA by e-International Publishing House, Ltd., UK.. This is an open access article under the CC BY-NC-ND license (http://creativecommons.org/licenses/by-nc$n d / 4.0 /)$. Peer-review under responsibility of AMER (Association of Malaysian Environment-Behaviour Researchers), ABRA (Association of Behavioural Researchers on Asians) and CE-Bs (Centre for EnvironmentBehaviour Studies), Faculty of Architecture, Planning \& Surveying, Universiti Teknologi MARA, Malaysia.

https://doi.org/10.21834/ajqol.v1i2.25 


\subsection{Drink Up the Water, Think of the Origin}

To protect the environment and to develop the economy have always been the most challenging and classic dilemma in every society at our modern time. With a problemsolving approach, this paper provides alternatives for balancing the dilemma. The research experiments how to revitalize a very depressed eco-protected district nearby the Capital Taipei of Taiwan. As the Taipei Water Special Area (TWSA), Pinglin located only $38 \mathrm{~km}$ northeast of the Capital Taipei (Figure 1). In order to protect the fresh water quality, no industry (not even hotels) could establish in Pinglin since 1979. Tea plantations and tea business have been the only way for residents to make living.
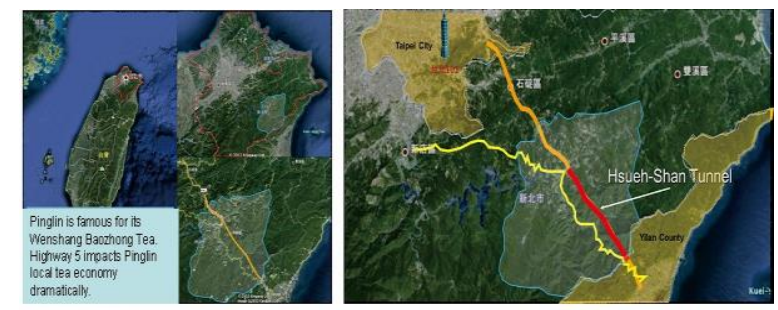

Figure 1: (L) Map of Taiwan. Taipei basin is highlighted in a red circle.

$\mathrm{R})$ The circled blue-circled area is the location of Pinglin

(Source: Author)

Marketing and selling Pinglin tea has been a critical issue for locals. Residents are mostly tea farmer families, since Pinglin has also been the oldest tea country in Taiwan. It was not so hard before 2006. Due to the surrounding mountainous landscape of Taipei basin, in old days, travelers had to meander through hilly mountains to get Pinglin and then its east neighbor county, Yilan. Therefore, Pinglin was the stop to Yilan before Highway 5 and the 12.9-kilometer Hsueh-Shan tunnel constructed in 2006. Unfortunately, nowadays after the tunnel opening to traffic, travelers have bypassed Pinglin so that the local tourism and tea economy has declined to thirty percent of the past since then. As a consequence, young people rapidly fled away from Pinglin; old farmers harshly struggle for living. At the same moment, Taipei people drink clean fresh water, but most citizens are unaware of the crisis in Pinglin relating to the water in their kitchen table glasses.

In order to revitalize the local economy without impacting the environments, the research team developed three ecological oriented method to revive Pinglin area. They are (1) product: eco-friendly fair-trade Blue Magpie Tea, (2) process: eco-tea tourism, (3) promise: eco-tea farmers' children tutoring. 


\subsection{Pinglin Identities: Feitcui Reservoir and Wenshan Baozhong Tea}

Pinglin as a place has been known for two identities: (1) the Feitcui reservoir and (2) the Wenshan Baozhong tea. The tea plantation terraces often associate with this quiet periurban landscape (Figure 2). Pinglin located in the northeast forested and mountainous area $(250 \mathrm{~m}$ to $800 \mathrm{~m})$ of the Taipei Basin within a portion of the Taipei Water Special Area (TWSA). The Feitcui Reservoir has been providing fresh water for 6.7 million Taipei residents in the capital Taipei since 1979. All the townships within the TWSA zone have been forbidden to develop any new buildings and industries. This new zoning control has been hard for people but good for the environment. The preservations of the natural environment have been successfully sustaining 316 animal species and healthy deciduous (broad-leaved) forest. Popular small size mammals include Civet Cat, Formosan pangolin, Emerald Green Tree Frog, Muller's Barbet, Formosan Whistling Thrush, Alcedo (Kingfishers), and Formosan Blue Magpie. The most famous tree species is Taiwan Acacia. Ferns are also very famous in this region because of the rainy climate.

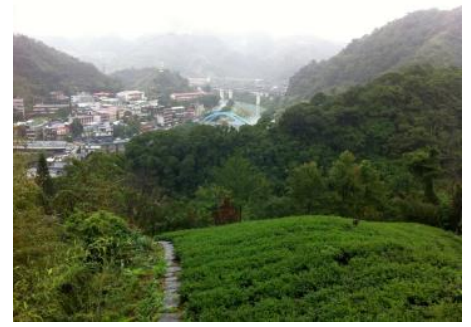

Figure 2: The relationship between tea traces and the Beishi Creek, the upper stream of the Feitsui Reservoir

(Source: Author)

While the reservoir has rigidly limited Pinglin's developments and people's quality of lives, the popular Wenshan Baozhong has provided the reasonable incomes for Pinglinians. So far, 80 percent of Pinglinians worked ast ea farmers in the area. The rest is also associated with tea productions and tea business. (Pinglin Township 2012) Due to its foggy and moist environment and hilly topography, Pinglin has been one of the best oolong tea cultivation areas in Taiwan. The so-called conventional tea cultivation depends on heavy applications of pesticides and fertilizers to keep the tea leaves with rich flavors. Therefore, even thought the zoning control has restricted new buildings and industries to move into Pinglin, its tea cultivation has been ironically toxic and pollute to the Feitsui Reservoir.

Taiwanese prefer oolong tea. According to Li (2012), nearly 70 percent of tea products consumed in Taiwan consist of oolong tea, of which of 80 percent is Pinglin Baozhong tea. The so-called Wenshan Baozhong tea (henceforth the Baozhong) baked from Qingxin oolong tea leaves and ranked as one of the top ten prominent teas in Taiwan. Dated back in Qing Dynasty around 1820s, the Qingxin oolong tea trees were transplanted from the 
southern region of China by Pinglin tea farmers' ancestors from Anxi in China (Niu 2004). Unlike usual ball-formed Chinese tea, Baozhong is known for its small spiraled-strip shape, the so-called little green dragon form. With its subtle honey taste, Wenshan Baozhong is popular within both Taiwanese and Japanese tea lovers. They appreciate the emerald leaf color with elegant smells plus the golden greenish tea soup.

Tea is hard to cultivate, especially to cultivate precious tea for picky Chinese tea lovers. Based on participatory observations and interviews, to preserve the extraordinary flavor and taste, the best champion tea leaves have to be juicy without pest bites (Chang 2012). According to Kawai (1997), tea plants are the targets for more than one hundred pests to attack, especially the plucking surface areas. He declares that the perennial and evergreen tea plants habit in the "most complex and most stable" agroecosystems among Japanese agriculture environments. Most pests of tea plants complete their life cycles within the tea fields. To establish eco-tea farming systems has to study the ecological chains of tea fields thoroughly. Kawai also argues that excessive insecticide applications might not be able to control tea pests because of the polyphagous nature of these insects. Instead, farmers should consider and experiment the conservation and utilization of indigenous natural enemies in the control system of tea pests. He recommends tentative IPM systems to be applied in Japanese tea cultivations. The Food and Agriculture Organisation of the UN (US EPA 2012) defines IPM as the careful consideration of all available pest control techniques. The subsequent integration of appropriate measures discourages the development of pest populations and keep pesticides and other interventions to levels that are economically justified and reduce or minimize risks to human health and the environment.

According to the field research, tea farmers usually prefer a conventional way of cultivating teas, because organic or environmentally friendly leaves would get bugs' bites. Those bites not only damage tea flavor, but also the beauty of leaves. No organic tea brands could participate in local or national tea competitions. However, only competition tea can get high profits in Taiwanese and Chinese tea markets (Lin 2012). In the case of Pinglin, among all tea farmers, only 6 percent of them are organic or/and environmental friendly tea farmers. Representing one of the six percent organic tea farmers, Mr. Lin only cultivates eco-friendly teas after he was hurt by pesticide and hospitalized for a week. Lin says, "about three years ago, I only touched a very tiny amount of diluted pesticide; my whole body got reddish spots and unendurable itch. I stay in hospital for a week. I never want to apply chemical stuff in my tea cultivations anymore."

In addition to pesticides, fertilizers also cause problems. Tea farmers apply substantial fertilizers to assure that they would harvest juicy tea leaves. Well-baked juicy tea leaves sustain good flavor even after serving several terms. Tea masters indicate that high-quality tea leaves could serve as many as seven to eight terms. The Director of the Feitsui Reservoir claims, " Local tea farmers over fertilize their farms. Tea trees could not absorb so many nutrients. The extra nitrogen and Phosphorus would wash into the Feitsui Reservoir that cause the eutrophication in the Reservoir." To address this issue, the Reservoir technicians have promoted the so-called "reasonable fertilization program" to tea 
farmers within the reservoir watershed. So far, dozens of tea farmers join the program. Tea farmers save money, while the reservoir reduces the level of eutrophication.

\subsection{Action Oriented Research: Social Innovations for Eco-Revitalizations}

The research aims to resolve the economic depressing of the environmental protected district in peri-urban Taiwan. The research team has engaged in the field since 2011. In addition to governmental documents and historical materials, there are action related engagements, including (1) Qualitative methods: the research team applied in-depth interviews, participatory observations, and ethnographic studies. And (2) Service learning Class based actions: both college and graduate levels interdisciplinary studio courses at National Taiwan University (NTU).

As mentioned earlier, this is a problem-oriented research that not only defines problems, but also searches for the solutions. In order to hunt solutions, professors at NTU have been offering interdisciplinary courses since 2012. Up to date, dozens of professors work together and co-teach five studios for more than hundreds of graduate students and upper-level college students. Both faculty and students are cross disciplines, to name a few, professors come from design and planning, geography, climate change, forest studies, and so on. Students come from science, humanity, agriculture, law, design and planning, etc. Students invent alternative ideas to revitalize Pinglin and assist eco-tea farmers. The group of design and planning students has even started up their social enterprise company for marketing the Pinglin's eco-friendly tea. In other words, students define that the socioinnovation for social enterprises is a key mechanism to revitalize this eco-protection zone.

\subsection{Blue Magpie Tea: Linking rural and urban, young and old}

To be successful of the eco-revitalization in Pinglin, we have to confront the challenge of today's consumer society where shopping and buying are the centers every civil life. Social innovation for the Pinglin tea country that integrates rural with urban, and young with old is the goal. Based on the service learning classes, the NTU faculty and students have developed three main strategies: (1) product: eco-friendly fair-trade Blue Magpie Tea, (2) process: eco-tea tourism, (3) promise: eco-tea farmers' children tutoring.

\subsection{Product: Branding the Blue Magpie Tea / an eco-friendly and fair trade innovation}

Marketing and package design the magpie tea has been the most critical step that our action trying to achieve (Figure 3). Astuti and Hanan (2011) point out design factors have profoundly influenced customers' preferences. From the strategic point of view, successfully marketing the Blue Magpie tea products have been as important as the development of environmentally friendly farming methods that explained above. The Blue Magpie tea 
packages have functioned as the best ambassadors symbolize the Taiwanese way to balance economy and ecology.

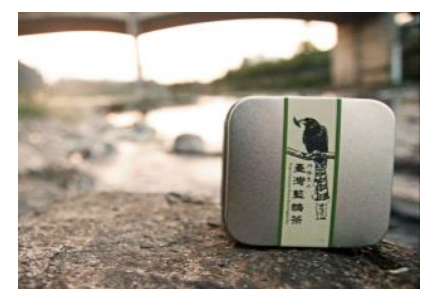

Figure 3: The Blue Magpie Tea product design version 4.

(Source: New Ruralism Social Enterprise Company)

The Blue Magpie Tea emphasizes fair trade relationship between tea dealers and tea farmers. Every spring, farmers and dealers get together and pin down the prices based on the group consensus. The dealers are the NTU students who decide to establish the New Ruralism Social Enterprise Company (NRSEC) to market the Blue Magpie Tea in 2013. So far, the NRSEC has sold more than 600 kilograms of the Pinglin eco-friendly tea.

Three principles are critical for the eco-friendly Blue Magpie tea (Figure 4). First of all, no pesticides allowed; only organic fertilizers applied, toxics free for birds' food chains. In other words, safe-pesticide and reasonable-organic-fertilizer applications are allowed in the magpie tea cultivation system. However, no toxic residuals are allowed to remain within bird food chains. Birds eat bugs, and bugs eat microorganisms in the soil. Therefore, chemical free soil environment is critical for sustaining a healthy food chain for birds. With the help from Pinglin eco-tea farmers, Dr. Tabata had done field research in the area in 2012. He identified that the larvae of Neolucanus swinhoei can only survive in soil without chemical containment. This Taiwanese native lovely little beetle's baby can serve as one indicator of chemical free tea cultivation environment.

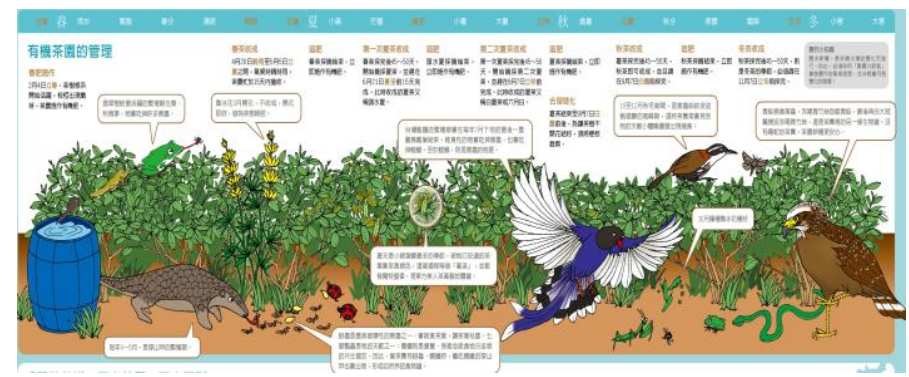

Figure 4: Ecological chain for the Blue Magpie TEAgriculture.

(Source: The BP NTU Pinglin Studio) 
Secondly, in order to protect topsoil, farmers plant green manure crops to manage weeds. Pinglin tea plantations are mostly hilly terraces. In conventional tea fields, no green cover protects topsoil, so that topsoil usually washed away by heavy rainfalls. Green cover plants, as well as green manure crops, are highly recommended for tea plantations. For example, Lupinus is a genus of flowering plants in the legume family (Fabaceae). It works very well as the spring green manure crops in Pinglin tea plantation. It contains rich nitrogen can contribute to tea leaves. Daylilies (Hemerocallis ) are better for autumn and winter, and it also good for steep slop due to its deep and comprehensive root systems.

Third, no new tea plantation developments are allowed. The magpie tea cultivation systems encourage farmers convert their conventional tea plantations to eco-friendly ones. Farmers should not cut forests and develop new tea farms for environmental friendly tea cultivations.

\subsection{Process: Experiencing eco-tea tourism I a culturally bond tea landscape innovation}

When the NTU students promote the Blue Magpie Tea to city dwellers, they realize most city people had very less knowledge about tea making. The NTU team initiated eco-tea tourism that guide city travelers to Pinglin tea country back in 2012. The learning tours teach participants Pinglin environmental context, the local economic crisis, the Baozhong tea cultivation, and the goal of the Blue Magpie Tea action. If the tea harvest season, participants could visit tea farms and picks up tea leaves. And then, follow tea farmers' guidance, they could do their green tea.

During the past two years, about dozens of groups join the tour. Participants are cross ages from newborn babies to 70 years old seniors. These Blue Magpie Tea friends consist of biker families, storytelling moms, café owners, college groups, high school students, environmental lovers, international scholars, and so on (Figure 5). Global visitors come from countries across three continents including: Europe (Norway, England, German, Greek, Ceska Republik), America (Canada, United States), Asia (Japan, China, Korea, Hong Kong, Thailand, Singapore, Malaysia, Indonesia, Philippine) and so on.

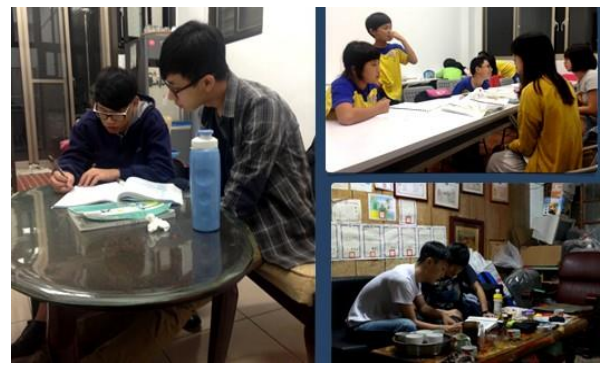

Figure 5: Eco-tea farmers' children tutoring programs in Pinglin.

(Source: New Ruralism Social Enterprise Company) 


\subsection{Promise: Tutoring eco-tea children / a rural educational innovation}

Losing young people is the most painful social crisis in Pinglin. Due to the gloomy economic outlook, all parents push their children to move to cities. The journey started from their middle or high school years. Even worse, all parents in Pinglin complain that their children could not get good education as urban children do.

Based on NTU's service learning courses, the NTU team has initiated volunteer tutoring program to serve the eco-tea farmers' children for three semesters since 2013. With the collaboration of the Pinglin Presbyterian Church, this tutoring program has been extended to many Pinglin families now. While farmers' children very much appreciate their volunteer tutors from NTU, all NTU students express that they have been learning a lot about rural life and farming from their students' families.

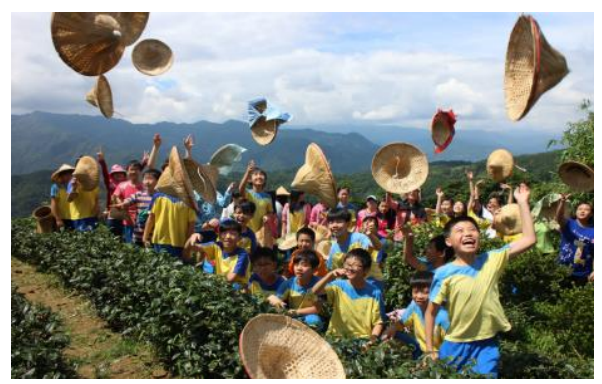

Figure 6: School children enjoy the eco-tea tourism at eco-tea farmer Mr. Liu-he Chen's tea plantation.

\subsection{Conclusion}

(Source: New Ruralism Social Enterprise Company)

The balance between environmental protection of the freshwater special zone and the local tea farmers' economics has always been challenging for planners and policy makers. This research takes an action orientated approach that proposes three directions: (1) product: eco-friendly fair-trade Blue Magpie Tea, (2) process: eco-tea tourism, (3) promise: eco-tea farmers' children tutoring. The Blue Magpie Tea actions have turned into a mini silent revolution, the so-called "Blue Magpie Tea revolution". It is quite well known among the young generation, especially college students and professors. Branding the eco-friendly "Blue Magpie Tea" has inspired the young coffee drinkers to taste tea. All actions help rebuild Pinglin's identity as an eco-tea country.

Tea cultivation and tea drinking have been historically integrating with Chinese civilization. According to tea history exhibition in the Iruma Museum in Japan, the earliest tea trees were found in Sichuan Province of the central China dated back at the beginning of the western calendar. During the past two thousand and more years, tea trees and the hobby of tea drinking have been gradually spreading worldwide. The participatory based Blue Magpie Tea action is one of many efforts that tea farmers and environmental activists have tried to eco-revitalize a depressing tea country. To sustain the goal, customers also 
have to be engaged in changing their drinking and consuming preferences. To reach a balance between ecology and economy, to link water with its origin, to tie people back to the land, everyone has to participate in the blue magpie actions. A small step, such as to share the blue magpie tea story when one drinks the tea with one's friends, functions as a critical environmental action that helps our habitat restoration within a big picture. Cheers!

\section{Acknowledgement}

This contribution was funded by the National Science Council (102-2410-H-002 -158 -MY2). Research assistants include Ren-zhi Huang, Po-chun Huang, ZeJun Young, and Ming-yang Kou. I very much appreciate their efforts for the comprehensive research work. All my appreciation also goes to volunteers of the Blue Magpie Tea movement, professors and students join the interdisciplinary curricula regarding Pinglin's eco-revitalizations.

\section{References}

Altieri, M. A. (1989). Agroecology: A new research and development paradigm for world agriculture. Agriculture, Ecosystems and Environment, 27, 37-46.

Altieri, M. A. (2002). Agroecology: The science of natural resource management for poor farmers in marginal environments. Agriculture, Ecosystems and Environment, 93, 1-24.

Astuti, S., \& Hanan, H. (2011). The behaviour of consumer society in consuming food at restaurants and cafes. Journal of ASIAN Behavioural Studies (ABS), 1(1), 73-81.

Chang, S. E. (2012). Pinglin Field Notes.

Kawai, A. (1997). Prospect for integrated pest management in tea cultivation in Japan. Journal of Agricultural Research Quartly, 31, 213-217.

Li, L.-w. (2012). Toward a self-sustaining energy management future: participatory planning for low carbon communities. Ph. D. Dissertation, National Taiwan University, Taipei, Taiwan.

Lin, W.-k. (2012). The effect of tea tasting contest in developing local tea industry: A case study of wenshan baozhong tea. Master Thesis, National Taiwan University.

Niu, C.-f. (2004). Wenshan Baozhong Cha. In United Daily News Local News Center \& Pinglin Tea Museum (Eds.), Traveling Tea Home Town in Taiwan (pp. 8-9). Taipei: Linking Publishing.

United Daily News Local News Center \& Pinglin Tea Museum (2004). Ravelling tea home town in Taiwan (pp. 89). Taipei: Linking Publishing.

US EPA. (2012). Integrated Pest Management (IPM). Retrieved Februray 11, 2013, from http://www.epa.gov/pesticides/factsheets/ipm.htm 